\title{
Computação Pervasiva: Ética, privacidade e segurança na Era da Internet das Coisas
}

Pervasive Computing: Ethics, privacy and safety in the Age of the Internet of Things

SANTOS, Dimitri; Mestrando; Programa de Pós Graduação da Escola de Design, Universidade do Estado de Minas Gerais (UEMG)

dimitribsn@gmail.com

CORRÊA, Patrícia; Programa de Pós Graduação da Escola de Design, Universidade do Estado de Minas Gerais (UEMG)

patriciaamorimbh@hotmail.com

REZENDE, Edson; Doutor; Programa de Pós Graduação da Escola de Design, Universidade do Estado de Minas Gerais (UEMG)

edson.carpintero@gmail.com

\section{Resumo}

Este artigo explora avanços tecnológicos nas comunicações enfatizando a Internet das Coisas. Problematiza questões éticas num mundo polarizado e interesses nas informações que circulam pelas redes. Mostra como empresas de comunicação detém mercados hegemonicamente, sanções governamentais antitruste, divergências entre setor público e privado e quebra de privacidade; bem como informações de usuários aplicadas para fins comerciais ou estratégicos. Ainda que as empresas ajam dentro dos marcos legais e agências de inteligência aleguem motivações lícitas para o monitoramento, personalidades como Snowden e os CEOs das gigantes da tecnologia travam um debate que merece atenção.

Este estudo evidencia uma realidade presente, situações cotidianas em que a sociedade está inserida sem se dar conta, num mundo interconectado. Aponta consequências dessa conectividade articulada por empresas norte-americanas na hipótese de um conflito global. Finalmente, propõe medidas para resguardar informações pessoais, e diretrizes para uma ecologia da informação favorável à Internet de Todas as Coisas.

Palavras Chave: Pervasividade; Ética; Privacidade; Internet das Coisas; Computação Ubíqua.

\begin{abstract}
This article explores communications advances emphasisizing transformations the Internet of Things announces. Also, ethical issues in a polarized world and interest in information in the mesh of networks. It shows antitrust sanctions to the largest communication companies; cites divergences between public and private sectors; privacy breach; information collected and applied for commercial or strategic purposes. Although companies act within legal frameworks and intelligence agencies claim licit reasons for the monitoring, Snowden and the CEOs of technology giants wage a debate that deserves attention.
\end{abstract}

This study shows an already present reality, depicting situations in which we are inserted, without 
realizing the consequences of a world widely interconnected. It points consequences of this connectivity articulated by companies based in North America in the verge of global proportions conflict. Finally, it proposes measures to protect personal information, and guidelines for an information ecology for the announced Internet of Everything.

Keywords: Pervasiveness; Ethics; Privacy; Internet of Things; Ubiquitous Computing. 


\section{Introdução}

A Internet de todas as Coisas: a próxima evolução da Internet está mudando tudo. Vivemos uma época de transformações abruptas em um ritmo inédito na história. Partindo da tecnologia digital, essa revolução atinge praticamente todas as áreas do cotidiano, de tal forma que o ano de 2017 vem sendo chamado de "o ano da Internet das Coisas". Cada vez mais a indústria incorpora tecnologias de comunicação aos objetos cotidianos de forma que o número previsto de objetos ou "coisas" conectadas até 2020 gira em torno de 34 bilhões (cálculo da Business Intelligence), com crescimento exponencial. Segundo Samuel Greengard, trata-se de um revolução que "promete mudar nossas vidas de uma forma mais rápida e profunda que qualquer tecnologia na história" (GREENGARD, 2015, p. xviii).

Dave Evans (2011) exalta as vantagens com que a internet das coisas atua e atuará ainda mais na vida das pessoas, apontando sua utilização em diferentes redes criadas para as mais variadas finalidades. Sistemas de segurança, controle e comunicação desenvolvidos e conectados para uma experiência descomplicada prometem à humanidade uma poderosa ferramenta de ajuda em praticamente todas as suas atividades. Entretanto, preocupações surgem ao percebermos aplicações indesejadas das informações disponíveis para alimentar esses complexos sistemas. Quem detém hoje o poder sobre a privacidade de usuários e cidadãos? Quais são os interesses por trás da coleta dos dados? Igualmente importante: o que eles sabem sobre você e, até que ponto isso é importante? Nas páginas que seguem o leitor é convidado a participar dessa discussão.

\section{Método}

Este artigo buscou informações acerca das transformações ocasionadas pela tecnologia digital nos últimos anos, bem como previsões e tendências referentes à Internet das Coisas e suas derivações, e às questões éticas e de privacidade envolvidas na gestão das informações pessoais dos usuários. $O$ estudo não busca esgotar a questão, mas problematizar algo que vem sendo encarado com muita naturalidade pela sociedade, uma vez que os potenciais benefícios e comodismo têm obliterado a percepção das questões subjacentes, carentes de mais ampla discussão na mídia e nas diversas esferas do Estado e da sociedade organizada (salvo talvez no cenário europeu).

Levantamentos foram realizados através de pesquisa de artigos utilizando os termos Pervasividade, Internet das Coisas, Ética, Privacidade, Ubiquidade e temas correlatos. Para artigos científicos foram consultados o Portal Periódicos (CAPES), o Google Acadêmico e o Google. Foram levantadas ainda notícias e postagens de blogs, bem como vídeos e livros representativos da temática. Entre os materiais pesquisados foram admitidos documentos, publicações e mídia nos idiomas português e inglês.

Paralelos e comparações das informações encontradas em discursos de pesquisadores, escritores, personalidades do universo da inovação e empreendedorismo, além de discursos de marketing de empresas e eventos noticiados foram consultados com vistas a responder à questão: a sociedade e seus líderes estão eticamente orientados para enfrentar a revolução em curso e para seus desdobramentos? 


\section{Discussão}

Um esforço relativamente silencioso e de enormes proporções vem sendo realizado no tocante à infraestrutura para a coleta, processamento e armazenamento de informações cotidianas de incontáveis usuários de sistemas de buscas e redes sociais. Nos próximos meses o Facebook baterá a marca dos dois bilhões de usuários (Statista, 2017) e recentemente substituiu seu lema "Making the world open and connected" pelo novo "Bring the world closer together" com foco na criação de comunidades.

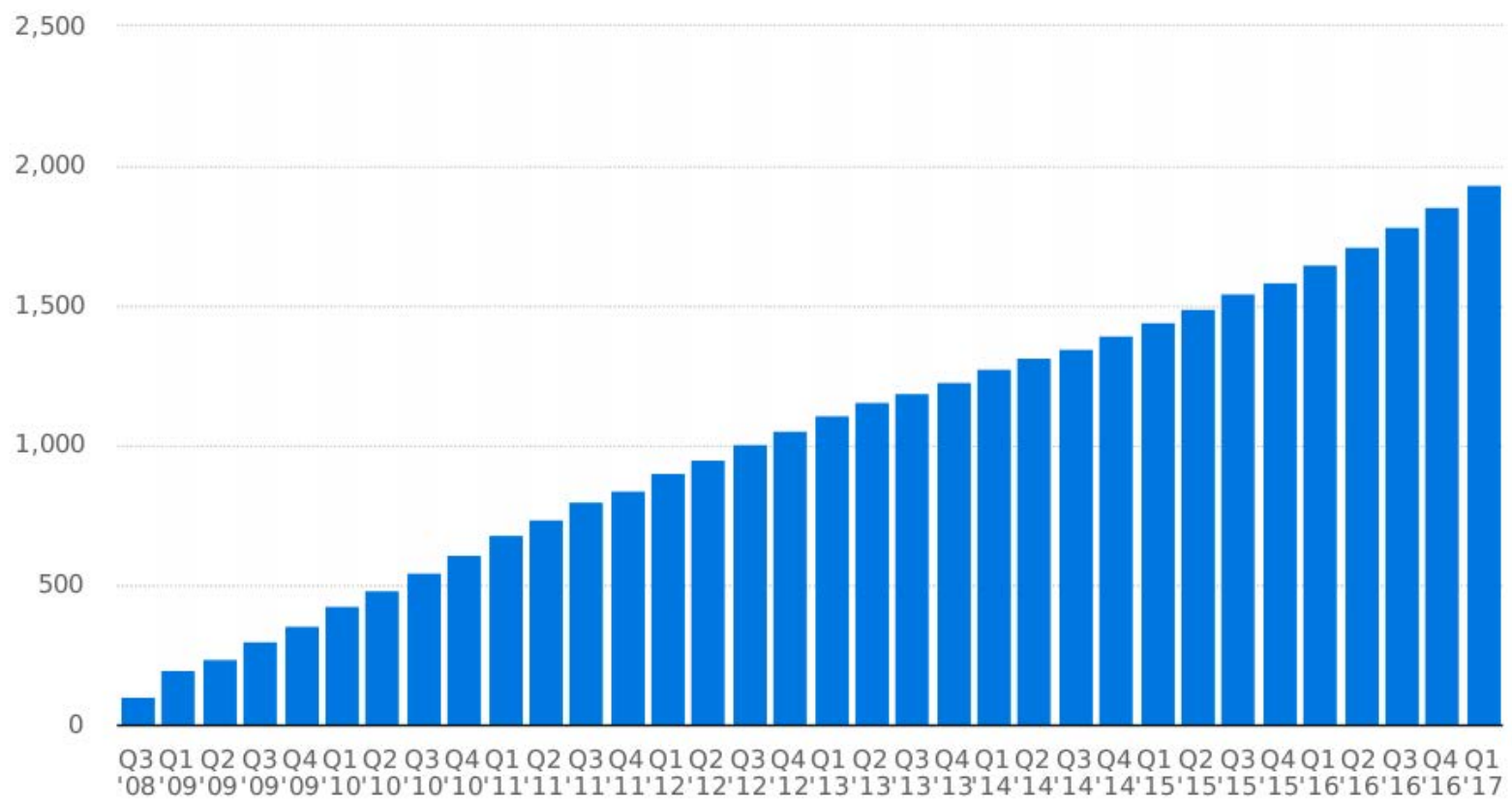

Gráfico 1: Número de usuários ativos mensais do Facebook em todo o mundo até o primeiro trimestre de 2017 (números em milhões de usuários), onde $Q=$ trimestre, segundo Statista.com (fonte creditada ao Facebook)

Enquanto isso o Google (controlado pela Alphabet) detém uma fatia em torno de $90 \%$ de todas as buscas de internet realizadas ao redor do mundo, e enfrenta na União Européia processos antitruste, entre outros, por favorecimento nos resultados de seu próprio sistema de comparação de preços de produtos. A multa recorde de 2,42 bilhões de Euros (a mais alta aplicada pela UE havia sido de 1,6 bilhão de Euros à Intel em 2009) acompanha a advertência para suspenderem o favorecimento em 90 dias ou enfrentarem sanções adicionais de até $5 \%$ do faturamento médio diário da Alphabet no mundo.

Se a ambição de conectar todas as pessoas no mundo (já expressa por Mark Zuckerberg) e o favorecimento estratégico de resultados nas buscas da grande rede não bastassem para sentirmos que estamos protagonizando uma realidade digna de ficção científica com rumos distópicos, a próxima fase dessa revolução não deixa dúvidas: máquinas e objetos que conversam entre si e percebem o mundo através de sensores para tomar decisões independentes de interferência humana já são uma realidade - e invadem progressivamente plantas industriais e de serviços, residências, automóveis e objetos de uso pessoal - pondo em cheque a questão da privacidade e a utilização ética desses dados. 
Embora os recursos para a criação dessa realidade fantástica pareçam ser ilimitados (estando as maiores empresas de tecnologia à frente do movimento, respaldadas por interesses de potências mundiais), devemos levantar a questão: o mundo está pronto para a Internet de Todas as Coisas? Nossas instituições têm maturidade para concretizar essa utopia ou estamos inadvertidamente caminhando para um cenário preponderantemente distópico?

\subsection{Pervasividade, Ubiquidade e Responsividade}

Na obra Arquitetura da Informação Pervasiva, Oliveira et al (Oliveira et al, 2015) apresentam o conceito de pervasividade da informação através da metáfora da água de uma represa que se rompe. "A natureza pervasiva da água represada se assemelha à natureza pervasiva da informação. [...] a informação digital invadiu a sociedade e a cultura, de modo que está presente nos espaços, ambientes analógicos e digitais, lugares web e não web, em diversos tipos de dispositivos, e modifica a vida dos sujeitos da mesma forma que a água da barreira que se rompeu modifica a vida dos sujeitos que encontrar pela frente". (OLIVEIRA, 2014, apud OLIVEIRA, 2015, p. 75). E Greengard (2015) corrobora com essa percepção quando propõe que "A Internet das Coisas vai tocar quase todos os aspectos de nossas vidas nos anos por vir".

Para melhor compreendermos este fenômeno, Oliveira (2014 apud Oliveira 2015) propõe ainda outras duas características da informação: a ubiquidade, que corresponde à capacidade da água de se integrar aos corpos assim como a informação se integra aos espaços e aos ambientes; e a responsividade, que refere-se à porosidade, ou à capacidade de absorção de água pelos corpos, ou seja, quanto os produtos tecnológicos (como tablets, smartphones, notebooks, televisão digital e tantos outros) estão aptos a captar e apresentar de forma adequada a informação digital.

\subsection{As bases para a Internet de Todas as Coisas}

O termo Internet of Everything (loE), atribuído à Cisco Systems, frequentemente é usado como sinônimo do termo Internet of Things (IoT) com uma conotação mais ampla, que abrange além da conexão entre os objetos ou máquinas (machine to machine - M2M ou Telemetria), também as conexões humano-máquina (human to machine - H2M). Ou seja, a soma de todos os sistemas conectados, incluindo a loT. Um desses sistemas, que promete crescer muito a curto prazo, é a Industrial Internet, termo cunhado pela GE para designar a interação entre máquinas, software, dados, análises e tecnologias sem fio com aplicações industriais. Outra vedete são os veículos autônomos, já funcionando no Vale do Silício onde a legislação foi atualizada para permitir seu uso e testes em situações cotidianas.

Mas o que é necessário para implementar essas tecnologias? Primeiramente é preciso um protocolo de comunicação, de preferência universal, que garanta a interoperabilidade entre os diversos produtos e sistemas de companhias diferentes. Atualmente é amplamente utilizado o IP (Internet Protocol) e para conexões e a tecnologia RFID (Radio Frequency Identification) para identificação e localização de produtos e equipamentos. Também ganharam expressão nas últimas décadas o uso de Geolocalização e GPS (Global Positioning System) permitindo o surgimento de tecnologias locativas, que respondem à localização do usuário ou dispositivo em tempo real. 
Um simples smartphone traz consigo diversos sensores diferentes, dedicados a perceber o mundo físico através dos níveis de iluminação RGB; gestos feitos pelo usuário com o aparelho; proximidade do ouvido ou superfícies; giroscópio (posição do aparelho); acelerômetro (movimento); geomagnético (bússola digital); temperatura e umidade; barômetro (pressão atmosférica) e efeito Hall (detecta se a capa do aparelho está abaixada ou levantada). Modelos recentes ainda contam com leitor biométrico (impressão digital); sensores de pressão que prometem eliminar os botões físicos; além dos mais óbvios: as câmeras frontal e traseira - que lêem códigos de barra, Códigos QR (Quick Response Code), capazes de reconhecimento de texto e até mesmo facial; microfone e tela sensível ao toque (inclusive multitoques). Considerando-se os conectores USB, BlueTooth, WiFi, GSM, NFS (Near Field Sensor) é possível conectar não só à rede telefônica, de troca de mensagens ou mídia e à internet, mas também a diversos dispositivos que adicionam ainda mais funcionalidades aos aparelhos, entre elas cameras infra-vermelho ou mesmo dispositivos de ultrassom portáteis, para citar alguns.

Essas são apenas algumas das possibilidades disponíveis para a loT, que se baseia nos conceitos de conectividade e sensores. A autonomia das "coisas" se apoia em sua capacidade de perceber o mundo e transmitir esses dados para que possam ser processados e interpretados conjuntamente, criando um contexto em que ações poderão ser tomadas independente da interferência humana. Contextos industriais por exemplo contam com sensores de fluxo, de químicos e gases; de força, carga, torque, tensão e pressão; de níveis e vazamentos; elétricos e magnéticos; e de vibração, além dos apresentados anteriormente e de toda sorte de inovações que não cessam de surgir.

$\mathrm{Na}$ outra ponta dos processos encontram-se os atuadores: dispositivos que permitem às máquinas executarem diversas funções operadas eletronicamente. Entre esses dois extremos há uma vastidão de possibilidades de coleta, processamento, tomadas de ação e interfaces homemmáquina possíveis, incluindo-se a tão controversa inteligência artificial e a sempre presente possibilidade de perda de controle de processos para invasores hackers ou interferências de toda ordem.

Esse complexo sistema é comparado a uma malha de conexões, e já existem tecnologias que permitem aos objetos atuarem como transmissores das informações geradas e enviadas por outros objetos, tornando a conectividade virtualmente onipresente - ou em outras palavras, ubíqua.

\subsection{Privacidade}

Embora não se abstenham os autores de discorrerem quanto a suas preocupações acerca do assunto, é John Thackara (2001) em seu O Desafio do Design na Computação Pervasiva quem melhor exprime a sensação geral de apatia diante da revolução iminente, quando usa a imagem do sapo colocado na panela com água fria sendo gradativamente aquecido até o cozimento sem se dar conta. Ele propõe que se trouxéssemos alguém do ano de 1800 para uma cidade ocidental da atualidade, certamente essa pessoa iria dar meia volta e fugir em estado de choque e aterrorizada diante dos avanços tecnológicos. Nós, pelo contrário, temos apenas a vaga sensação de que as coisas estão esquentando sem nos incomodarmos com isso.

Se para Greengard (2015) os ganhos não virão sem uma boa dose de dor - e uma abundância de consequências indesejadas; Thackara é mais pungente e questiona a validade dessas 
transformações quando diz que "estamos enchendo o mundo de sistemas e dispositivos fantásticos, mas temos dificuldades em explicar para que servem essas novidades, ou que valor adicionam a nossas vidas" (Thackara, 2001, p. 48) e cita Bruce Sterling, escritor de ficção, que tão bem expressou preocupações muito atuais no trecho "você irá sair para observar as flores no jardim, e o jardim irá observar você".

O que será da privacidade em um mundo tão extensivamente conectado? Quais as consequências para o cidadão comum? Com prospectos de distopia Orwelliana, nosso presente já aponta questões importantes em discussão ao redor do mundo, expressas por Greengard (2015, p. xv) na certeza de que a loT "levará nossa sociedade a examinar mais de perto as noções de privacidade e segurança".

Em Junho de 2013, o caso Snowden trouxe à tona denúncias de espionagem a líderes mundiais e cidadãos comuns conduzidas pela NSA, agência americana de inteligência, que perturbaram o mundo. Na vanguarda das discussões sobre privacidade e a vigilância global norte americana, ele declarou ao Yahoo Global News, em entrevista gravada em Moscou em 3 de dezembro de 2016, que "Em 2013, antes disso começar [referindo-se às repercussões de suas denúncias], a ideia de que o governo estava coletando registros de todas as ligações telefônicas nos Estados Unidos era apenas uma teoria da conspiração. Já não é mais." Anteriormente, em outubro de 2015, a BBC já havia televisionado o quadro de 30 minutos "Edward Snowden: Espiões e a Lei" em que o ex-agente alerta para ferramentas que a NSA possui para sequestrar smartphones, acionando remotamente aparelhos mesmo quando desligados, e capturando imagens de suas câmeras e até o som ambiente através dos vários microfones presentes nos aparelhos independente de estarem em uso ou no bolso do usuário. Se alguém precisa garantir sua privacidade, Snowden recomenda abrir o aparelho e extrair as câmeras e microfones manualmente, passando a utilizar um fone de ouvido com microfone para falar, exclusivamente durante as chamadas.

Mas o cidadão comum poderá argumentar que não tem nada a esconder. Esta é uma postura perigosa diante dos rumos das políticas sobre privacidade e da conjuntura internacional atual. Snowden aponta as pressões e ameaças de embargos e retaliações americanas como explicação, e adverte em duas passagens dignas de nota, extraídas da já citada entrevista ao Yahoo Global News, sobre a gravidade do tema:

\footnotetext{
"Privacidade é o fundamento de todos os outros direitos. Eu diria que argumentar que você não se importa com privacidade porque você não tem nada a esconder, não é diferente de dizer que não se importa com a liberdade de expressão porque você não tem nada a dizer." (Tradução nossa)
}

Qualquer nação que em alguma instância se oponha aos interesses hegemônicos atuais, ou seja acusada de envolvimento com terrorismo (seja a acusação procedente ou não) pode enfrentar sérias complicações. O próprio Snowden alega ter buscado asilo em 21 países ao redor do mundo, incluindo aqueles com as legislações mais avançadas sobre privacidade digital na Europa, sem qualquer sucesso, ocasião em que acabou obrigado a permanecer em solo russo onde pretendia fazer escala ao ser banido de Hong Kong.

\footnotetext{
“Como nossos patronos fundadores disseram: 'Aquele disposto a sacrificar sua liberdade essencial por alguma pouca satisfação temporária, não merecerá e não alcançará nem uma nem outra'. Isso representa bastante aquilo para quê estamos despertando: a ideia de que, em muitos sentidos, o público perdeu seu assento à mesa no governo como um sócio
} 
igualitário."

Embora seja enaltecido como herói por legiões de fãs ao redor do mundo, em solo americano é considerado traidor da nação e possível espião de cada país que lhe oferece asilo ou apoio. O novo secretário de inteligência apontado por Donald Trump já se posicionou afirmando que ele deveria ser executado.

Um atentado ocorrido nos Estados Unidos em dezembro de 2015 ficou conhecido como San Bernardino Shooting, quando um atirador com a ajuda de sua esposa assassinou 14 pessoas a tiros. Em fevereiro de 2016 o FBI apresentou ordem judicial à Apple visando obter acesso facilitado aos dados criptografados do iPhone, aparelho utilizado pelo assassino, com a justificativa de poder levantar relações do atirador com grupos terroristas. A Apple no entanto resistiu ao pedido de fornecer os meios para facilitar a quebra de sua criptografia, o que exporia todos os seus usuários, e o caso repercutiu amplamente na mídia.

A criptografia em aparelhos vem sendo reforçada pelas empresas de tecnologia desde as denúncias de espionagem global pela NSA no caso Snowden. Houve tomada de partido sobre o tema: Zuckerberg apoiou a postura da Apple dizendo "eu não penso que construir backdoors seja a solução, por isso somos solidários ao Tim e à Apple" (referindo-se ao presidente executivo da Apple Timothy D. Cook). Por outro lado Gates destacou a importância de o governo garantir a salvaguarda dos cidadãos e comparou a situação a um pedido pontual de quebra de sigilo bancário ou telefônico. O presidente da MicroSoft concluiu: "Isso nos dá a oportunidade de termos essa discussão e as questões serão decididas no Congresso".

Toda essa discussão levou as grandes empresas de tecnologia a se reposicionarem publicamente, e resistirem em alguma medida às coerções dos órgãos de inteligência dos Estados Unidos, onde estão concentradas no vale do silício. Oferecem resistência ao livre acesso a dados pessoais de seus usuários, de forma que o uso de criptografia e sua complexidade vêm aumentando. Hoje a Apple e empresas concorrentes e de mídia social possuem suas páginas dedicadas ao tema privacidade. Cada uma a seu modo busca aumentar sua credibilidade e a confiança dos usuários no sigilo de suas informações.

Embora seja razoável que a quebra do sigilo possa ser demandada pelos devidos canais legais, em casos de interesse público e de segurança nacional ou internacional, como saber o que está sendo automaticamente coletado e armazenado a nosso respeito?

Em junho de 2015 o Google lançou uma página chamada My Account (minha conta) onde os usuários podem ter um vislumbre de suas informações pessoais, de busca e acesso coletadas pela companhia. Ali é possível inclusive alterar suas configurações, que cobrem desde histórico de buscas (incluindo áudios de pesquisa por voz e suas transcrições) e de acessos a sites, até configurações de anúncios inteligentes oferecidos por terceiros com base em seus hábitos online e um extenso arquivo de geolocalização com sua navegação física apresentada em um mapa dia após dia. Sim, "O Google sabe muito sobre você, certo? E de quem é a culpa? Sua, claro" - afirma Lee Munson, especialista em segurança, em matéria de Yolanda Valery para a BBC Mundo datada de 6 de julho de 2016 e intitulada: Como descobrir tudo que o Google sabe de você - e como apagar seu rastro.

A matéria dá o passo a passo que promete desarticular a coleta automática dos dados (pelo menos de forma explícita e consentida), além de ensinar como baixar um arquivo contendo "toda a informação que a empresa guarda sobre você". Horas após a solicitação (que a empresa alega poder render dias de espera dependendo do caso) a repórter obteve arquivos em seu Gmail contendo 
entre outras coisas, todos os seus e-mails, e nas palavras dela: "o Google ainda tinha as fotos. Todas que a repórter havia feito com seu telefone nos últimos dois anos. Deletadas ou não, compartilhadas ou não." Como isso é possível? Simples. A Google detém entre outras plataformas, o sistema Android, que opera na maior parte dos smartphones do mercado.

Embora a empresa alegue proteger os dados de seus usuários e garantir seus direitos de autoria sobre conteúdos depositados no Google Drive por exemplo, ela obtém a possibilidade de acesso a essas informações, o que de outra forma seria impossível. Toda essa informação disponível "É uma mina de ouro. Para o Google, representa bilhões de dólares", aponta Jonathan Sander, vicepresidente da Lieberman Software, consultado na matéria. E isso é tudo feito dentro da legalidade? Sim, desde que o usuário concorde com os termos e condições, que raramente lê. Neste caso, entrega de bom grado suas informações. Ainda assim a União Européia tem enfrentado a gigante da tecnologia em questões de privacidade, monopólio, direito de esquecimento e coleta de dados, tendo aplicado sanções e multa, embora geralmente tenha sido considerado que a gigante das buscas vem operando dentro do marco legal.

A estratégia parece clara: tornar-se indispensável oferecendo produtos em grande parte gratuitos para enormes parcelas da população mundial (e instituições) e, em contrapartida, acessar irrestritamente dados compartilhados voluntariamente - ou inadvertidamente. Recentemente se reorganizaram sob uma nova marca chamada Alphabet que passou a controlar a Google e diversos dos braços da empresa que não tinham tanta relação com sua principal atividade fim. Entre elas está a Nest - produtos inteligentes para o lar, indicando que seu interesse na intrincada malha da Internet das Coisas vai muito além das buscas, serviços online ou dos smartphones. Ela promete marcar presença em nossas casas por meio de câmeras de segurança, termostatos e sensores de fumaça compatíveis com outros sistemas da companhia e parceiros de automação residencial. 0 selo "Works with Nest" denota padrões de interoperabilidade entre os mais diferentes utensílios de diversas marcas, todos oportunamente operáveis sem dificuldades a partir do smartphone, e capazes de "aprender seus hábitos e preferências". Se genial ou maquiavélico, só o futuro dirá.

\subsection{0 mundo está preparado para o futuro?}

Se por um lado Bill Gates declara abertamente que Snowden não é nenhum herói, Zuckerberg apoia a resistência da Apple em criar um backdoor que garantiria aos agentes acesso não apenas aos dados de pessoas investigadas e envolvidas em questões tramitadas no judiciário, mas de todos seus os usuários. Mais recentemente Assange, fundador do Wikileaks interferiu nas eleições disputadas entre Hillary Clinton e Donald Trump pela presidência americana, publicando emails vazados da candidata, ao ponto de a embaixada do Equador em Londres, onde reside em asilo político, cortar seu acesso à internet na reta final da disputa. Paralelamente tornam-se comuns incidentes envolvendo drones e privacidade, bem como disseminaram-se no espaço aéreo balões e satélites de captação de imagens para empresas como a Google; vazamentos frequentes de informações e mídia pessoais, além do sequestro de dados de grandes empresas e instituições públicas e privadas na forma de ransomware por hackers vêm sendo noticiados e mostram um despreparo generalizada de governos, empresas e autoridades para lidar com a fragilidade da privacidade dos cidadãos e até de seus líderes. 


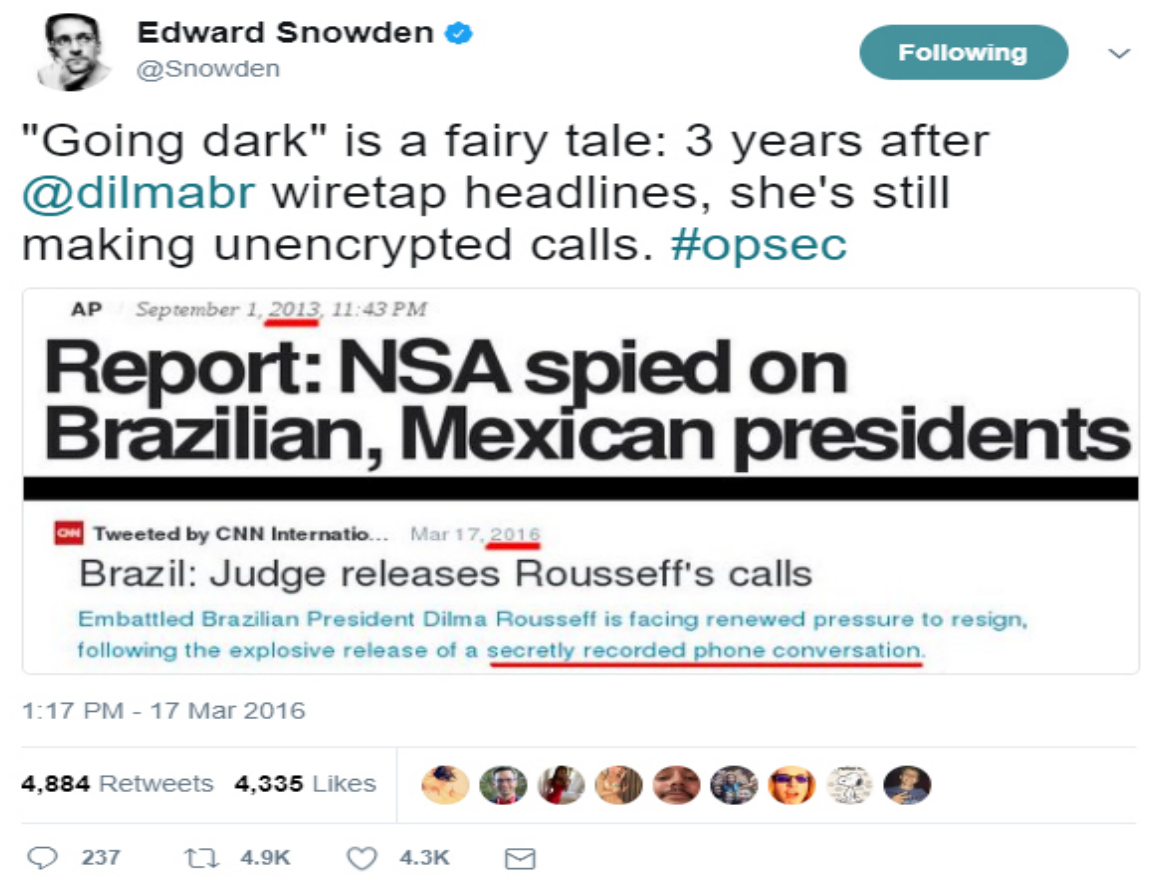

Figura 1: Tweet de @Snowden de março de 2016 destacando que mesmo depois das denúncias de espionagem 0da NSA ao governo brasileiro em 2013 a presidência não adotou criptografia em suas comunicações

\subsection{O fenômeno da Internet das Coisas já começou}

Inúmeras são as narrativas propondo cenários utópicos baseados nos avanços da comunicação digital e seu mais novo chamariz, a Internet das Coisas. Vídeos simulando um dia na vida de um cidadão comum nas próximas décadas são apresentados por diversas empresas envolvidas nos processos de implementação e gestão dos objetos interconectados. Parte dessa realidade já existe e temos disponíveis na internet numerosos vídeos com testemunhos, demonstrações e simulações de entusiastas da tecnologia defendendo a praticidade de um mundo em que tudo está conectado.

Mark Zuckerberg postou no Twitter como meta pessoal de ano novo para 2016 desenvolver um assistente de Inteligência Artificial para sua residência que ele comparou ao assistente JARVIS do personagem Tony Stark da Marvel - de quem emprestou o nome. Vídeos apresentando a empreitada podem foram publicados com ar de provocação, enquanto a página de desenvolvimento do programa foi publicada e mantida atualizada pelo CEO do Facebook dentro da própria plataforma - contribuindo para o esforço geral de evangelização de seguidores do movimento.

Tanto a Internet, quanto as grandes empresas de serviços de buscas e mídia social estão presentes em praticamente todo o mundo. Quando pensamos em uma rede global pervasiva e virtualmente ubíqua, devemos levar em conta as diversas possibilidades de aplicação dessa rede e os interesses envolvidos. A loT propõe uma integração ainda maior entre o mundo virtual (online) e a realidade concreta ao embarcar sensores e conectividade aos mais diversos objetos de uso cotidiano e lançá-los no mercado mundial. 


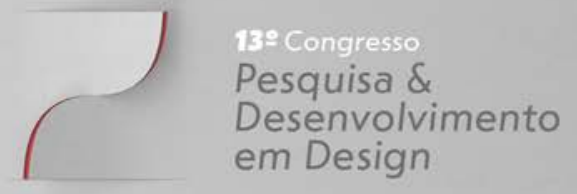

Artigo Completo

Greengard (2015) apresenta em A Internet das Coisas que em novembro de 2013 a Amazon anunciou seus planos para operar entregas utilizando drones, e que já em 2009 o presidente da FedEx Fred Smith havia declarado que o futuro das entregas estava nas esquadrilhas de drones. No entanto o autor destaca que desde 2014 a Administração Federal de Aviação americana baniu o uso de drones comerciais para entrega de encomendas no futuro próximo. Evidente que a regulamentação e a segurança desta atividade emergente constituem assunto complexo e delicado, num cenário em que mesmo aviões tripulados já foram utilizados como armas em ataques atribuídos a terroristas.

Grupos terroristas são uma constante nas manchetes e discursos políticos, inclusive favoráveis à quebra de privacidade dos usuários. Mas devemos nos preocupar também com os interesses conflitantes de grandes nações. Em 16 de outubro de 2016 o presidente russo Vladimir Putin anunciou aos jornalistas do Kremlin "os EUA estão monitorando vocês" referindo-se à vigilância dos serviços de inteligência americanos sobre a imprensa russa, e adicionou: "os Estados Unidos tudo ouvem e tudo vêem. Todos vocês podem ser alvos de investigação pelos serviços especiais".

O cenário internacional, a despeito das experiências relativamente recentes das grandes guerras, parece aguardar apenas o estopim para a eclosão de uma crise global sem precedentes. Ações hostis estão sendo constantemente deflagradas originando um receio geral de que as os conflitos dos Estados Unidos com países como Coréia do Norte ou do Oriente Médio não sejam resolvidos numa mesa de negociações como em 1962. As agendas conflitantes põem em questão se estamos realmente prontos para nos conectarmos tão abertamente a todas as coisas, como propõe a Internet of Everything.

Claramente haverá simpatia às razões levantadas em defesa da quebra da criptografia e do sigilo do aparelho no caso apresentado. Situação análoga a dos ataques de 11 de setembro de 2011, que ajudaram a justificar a instauração da vigilância global do programa PRISM da NSA americana.

Embora o discurso antiterrorista represente amplamente os interesses de boa parte do mundo, vem sendo evidenciado que tais recursos não são utilizados exclusivamente na guerra ao terror. Mais do que isso, essa bandeira parece ter-se tornado uma espécie de propaganda ideológica utilizada para acobertar toda uma agenda de ações estratégicas no campo da inteligência e das intervenções em conflitos como os do oriente médio. Delegar a regulação de questões que afetam todo o mundo exclusivamente a uma nação com interesses políticos e comerciais próprios, e toda uma história de violências contra os direitos humanos, seria no mínimo arriscado.

\subsection{Onde pode chegar a Internet de Todas as Coisas?}

Na hipótese não muito remota da eclosão de uma Terceira Guerra Mundial poderíamos nos perguntar se as maiores empresas de tecnologia do mundo (sediadas nos EUA) teriam algum protagonismo - e que consequências isso traria aos usuários. Presentes no dia a dia de bilhões de pessoas, propõem-se agora a conectar plantas industriais, automóveis e residências amplamente, 0 que pode parecer fantástico num cenário de calmaria, mas que não sabemos dizer em que poderia se converter na ocasião de um conflito.

Recentemente ataques hackers desarticularam o sistema bancário da Ucrânia, além de sequestrarem diversas informações e sistemas pelo mundo demandando pagamentos para a 
devolução dos dados e normalização dos serviços. O que seria possível às empresas de tecnologia caso se propusessem a desarticular determinado grupo? Pensemos nos sistemas operacionais de computadores e dispositivos móveis apenas, e teremos uma ideia vaga de seu potencial.

O canal History propõe um exercício imaginativo de como se daria esse enfrentamento e lista entre as possíveis estratégias o uso de robôs e drones que permitem controlar remotamente armas ou equipamentos militares. Além disso, propõe que também no ciberespaço seriam travadas batalhas utilizando-se as redes sociais para denunciar ou formar opinião, facilitando o acesso imediato a documentos de todos os tipos. E ilustra como a manipulação da opinião pública será possível através das informações fornecidas por equipes de hackers, muitas vezes financiadas pelos governos.

O cenário é preocupante nas relações internacionais, com as sanções à Coréia do Sul por sua pesquisa em armamentos nucleares, especialmente em face à confusão interna do governo americano se encontra na administração de Donald Trump - que recentemente demitiu o diretor Comey do FBI por motivos controversos - incluindo a investigação do atual presidente durante a gestão Obama.

\subsection{Uma realidade digna de obra de ficção científica}

Na contramão do afã tecnológico foi justamente a obra de George Orwell - 1984 que Robert Colls (2013) resgatou para traçar um oportuno paralelo com a denúncia feita por Edward Snowden trazendo a público o programa norteamericano de espionagem em massa, o PRISM. Colls compara o sugestivo nome da agência à Pirâmide monstruosa em que trabalha o protagonista da ficção. $A$ ideia de um prisma ou pirâmide sugere um controle central no ápice de uma estrutura de base ampla e abrangente - exatamente o que o programa de espionagem parece ter sido capaz de fazer ao exigir das maiores empresas detentoras de informações (como Google, Apple, Facebook e Yahoo) a quebra de sigilo de seus usuários e colaboração com sua vigilância global.

Já o escritor Dave Eggers revisitou a questão do Grande Irmão lançando a obra O Círculo (2013) que chegou às telas do cinema em 2017. Num cenário em que ficamos perdidos entre o futurístico e o contemporâneo, o diretor James Ponsoldt retratou as questões mais atuais acerca da privacidade diante dos desenvolvimentos tecnológicos característicos de nossa época. Na fiç̧ão, uma rede social hegemônica (já realidade) lança mão de micro câmeras sem fios, sempre conectadas e energeticamente autônomas, braceletes e até nanotecnologia intra-corporal para monitorar cidadãos e funcionários vinte e quatro horas por dia - e propõe ainda a lideranças políticas e empresariais "tornarem-se transparentes" como solução para a corrupção entre outras coisas, significando transmitirem suas vidas pública e particular na íntegra $99 \%$ do tempo ao público via internet. Com a máxima "segredos são mentiras", o enredo propaga a ideia de que "saber é bom, mas saber tudo é melhor" na solução dos problemas da humanidade, e deixa para o fim uma proposta difícil de aceitar: o absoluto fim da privacidade. Será este o futuro que queremos?

Figura 2: impressões dos campi circulares extraídas do trailer de O Círculo $(A)$ e da capa da revista Wired de Junho de 2017 que apresenta o Apple Park contendo o Apple Campus 2 (B) 

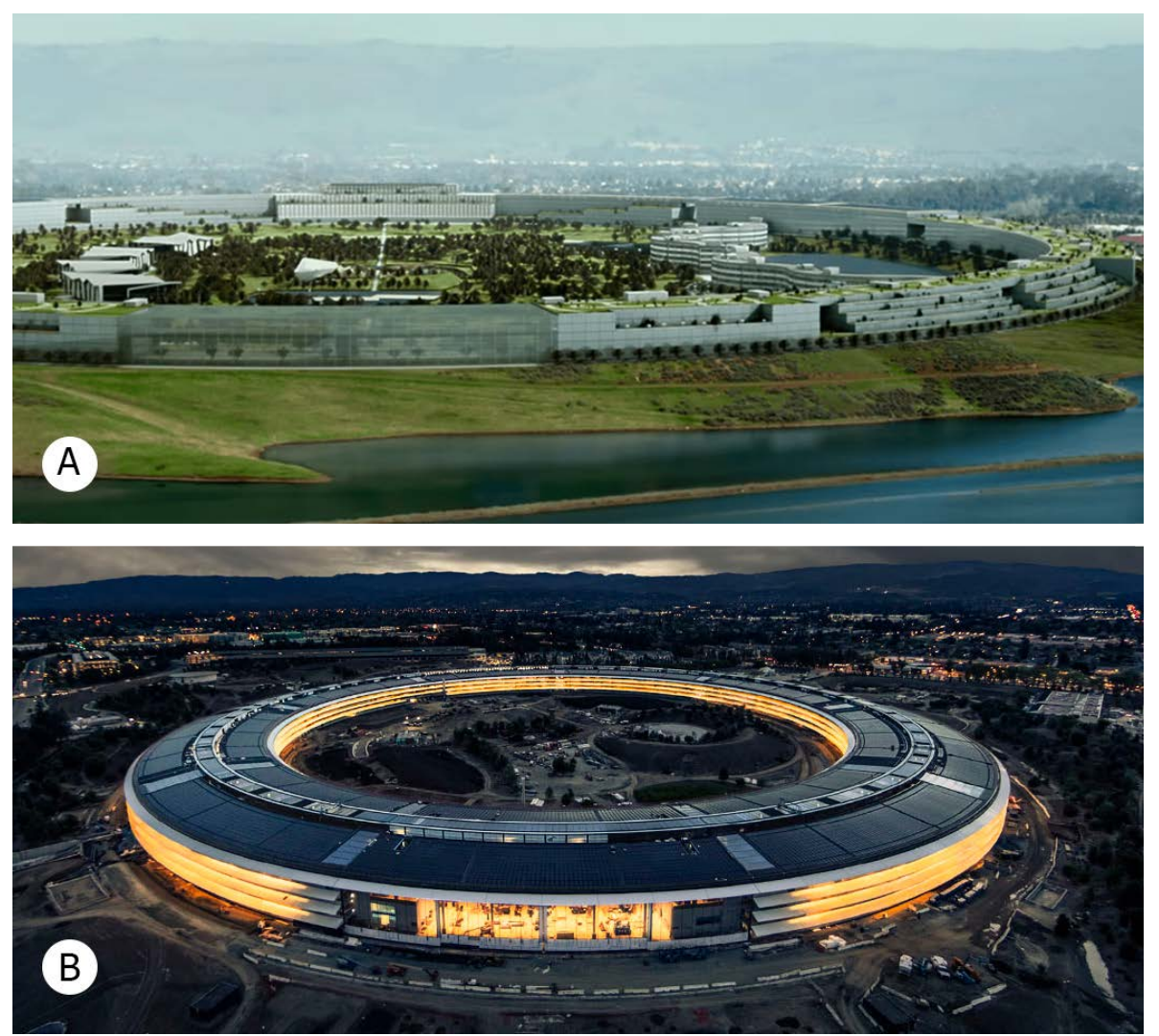

(fotografia de Dan Winters)

Curiosamente, o filme figura um complexo de escritórios circular que remete imediatamente ao novo Apple Campus 2 já sendo ocupado mas ainda em fase de finalização. No entanto, o fictício TruYou - serviço que reúne todas as senhas no longa-metragem, simplificando a internet - guarda mais semelhanças com a realidade atual da Alphabet, controladora da Google, Nest e YouTube, e em seu aspecto de rede social nos remete imediatamente ao Facebook. A Internet das Coisas se mostra operativa no filme, conectando toda sorte de dispositivos e guardando volumes imensuráveis de dados em servidores controlados pelo Círculo. É impossível não relembrar a entrevista divulgada em 8 de julho de 2013 em que Edward Snowden explica por que havia colocado em risco sua vida e desistido de sua carreira ao denunciar o esquema de espionagem da NSA, dizendo: "Eu não quero viver em um mundo onde tudo o que eu falo, tudo o que eu faço, todo mundo com quem eu converso, toda expressão de criatividade, amor ou amizade, tudo seja gravado". A personagem de Emma Watson não parece concordar, o que leva a ponderar: qual será a opinião pública atualmente? E o que pensarão dessas questões as próximas gerações?

\subsection{Lideranças da revolução}

A partir das questões de privacidade levantadas podemos comparar os discursos dos CEOs da Apple e do Facebook quanto à privacidade de seus usuários por oportunidade do D8 Conference 2010**. Enquanto Steve Jobs mostra uma opinião madura apoiada no direito do usuário em concordar em ceder ou não seus dados e informações a cada evento que as demande; Zuckerberg é surpreendido e não consegue elaborar uma resposta satisfatória para a entrevistadora que indaga 
"você sente que está violando a privacidade das pessoas?" e protagoniza alguns dos momentos mais embaraçosos de sua carreira, nitidamente gaguejando e suando diante do inquérito televisionado para o qual não estava preparado.

Gráfico 2: Apps móveis mais populares de redes sociais nos Estados Unidos em maio de 2017, por usuários ao mês (valores em milhões, visitantes únicos) segundo Statista.com

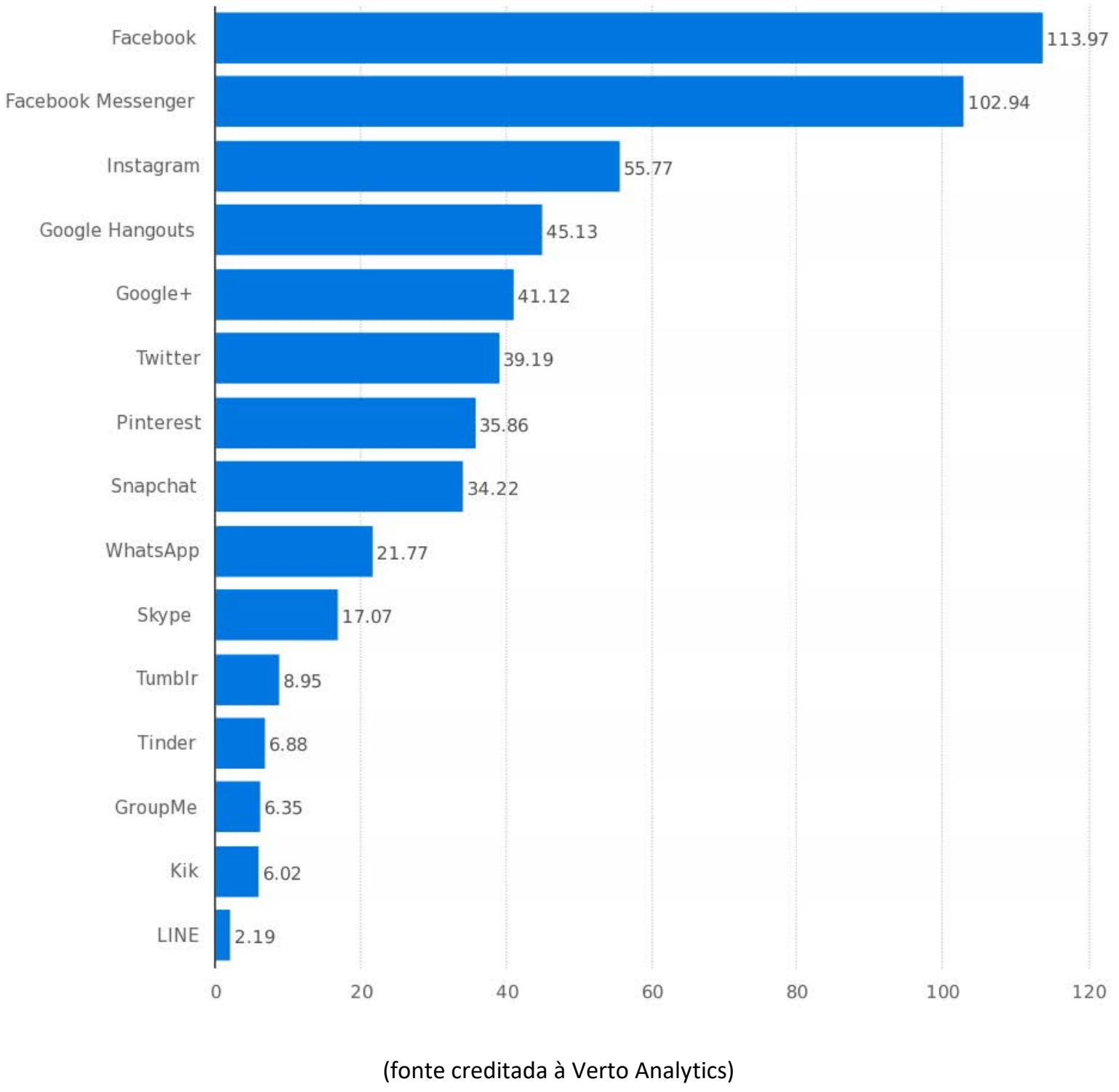

\section{9 Ética}

Fato é que estamos muito envolvidos com os serviços de tecnologia, seja em nossas casas, no nosso trabalho e até mesmo nos momentos de lazer.

Não é mais possível espalharmos inocentemente nossos dados pessoais, confiando na integridade daqueles que gerenciam essas informações. Vazamentos e usos abusivos de dados já ocorreram deixando à mostra a fragilidade dos sistemas, alertando tanto os consumidores quanto às empresas, sendo que essas últimas estão desenvolvendo cada vez mais recursos de segurança que garantam a tranquilidade dos seus consumidores e visitantes. 
Vários crimes vêm sendo cometidos, à revelia das leis que deveriam deles nos proteger. Dentre estes crimes, convém citar aqueles que ferem diretamente a ética.

A facilidade com que acontece a comunicação entre as pessoas, fisicamente muito próximas ou muito distantes, trazem consequências tanto positivas quanto negativas. Vale reconhecer os benefícios alcançados advindos desses instrumentos praticamente em todas as áreas que envolvem a sociedade, a saber, educação, política, cultura em geral, trabalho e comércio. A internet praticamente eliminou os limites que postergavam as respostas, o diálogo e as opiniões dos indivíduos. Tudo acontece tão rapidamente que vale uma reflexão sobre seu uso consciente e ético. Infelizmente, não vemos todas essas benesses usadas para o que deveria ser um bem para todos. $\mathrm{Na}$ contrapartida estão seu uso para interesses escusos e oportunistas, com prejuízos não apenas materiais, mas também morais. O mesmo não se dá apenas no nível pessoal, mas atinge entidades, empresas e nações inteiras.

Quando percebemos que potências mundiais se utilizam da facilidade dos meios de comunicação para formação de opinião e controle dos povos, devemos ficar alertas. Adriano Duarte de Rodrigues adverte em seu livro Estratégias de Comunicação (Lisboa, 1990), que "em alguns casos instrumentos de comunicação são inventados primeiramente com fins militares e só depois são explorados comercialmente pelos civis".

Apenas o uso ético das informações garante o verdadeiro bem comum, o crescimento e o desenvolvimento que promovem a paz para a humanidade. Quando todos de fato colaborarem uns com os outros, e as nações lidarem umas com as outras com justiça e respeito, muito se terá avançado. Há aí um longo caminho a ser percorrido. Para que isso aconteça na prática é necessário que empresas e governos respondam positivamente à confiança neles depositada por seus usuários.

Problemas que interferem na segurança, privacidade e direitos autorais, demandam constante observação, cuidado e ações que de fato os eliminem, a fim de que todos possam usufruir dessa ferramenta poderosa que, se bem utilizada, contribuirá ainda mais para o desenvolvimento, a interatividade e a união dos povos.

\section{Conclusão}

Nossa sociedade ainda luta contra preconceitos de naturezas as mais variadas, e embora tenha nuances de uma Aldeia Global, conforme anunciada por McLuhan, ainda encontra-se marcada por crises, polarizações e incidentes político-econômicos, diversos focos de conflito armado, ditaduras, desigualdades, desinteresse no combate à miséria e as maiores dificuldades no enfrentamento sistêmico às questões ambientais. Sem falar no ressurgimento de uma Guerra Fria tardia e a intrincada questão da cruzada contra o terror. Avançamos muito nos aspectos tecnológicos e parecemos embriagados pelas possibilidades que se abriram (e se abrem a cada dia) diante de nossos olhos.

\section{Referências}

OLIVEIRA, HPC, VIDOTTI, SABG, and BENTES, V. Arquitetura da informação pervasiva. In: Arquitetura 
da informação pervasiva [online]. São Paulo: Editora UNESP; São Paulo: Cultura Acadêmica, 2015, pp. 75-105

(OLIVEIRA, Henry; VIDOTTI, Silvana; BENTES, Virgínia. Ed. UNESP, 2015. Arquitetura da Informação Pervasiva. Ed. UNESP, 2015. Cap. 3 pág 75-105 como transformar informação em um negócio lucrativo. 2. ed. São Paulo: Editora Campus, 2007. 142 p.

DE MORAES, Dijon e KRUCKEN, Lia (organizadores). Cadernos de Estudos Avançados em Design: Transversalidade - Caderno 2, Vol. 1. Belo Horizonte: Ed. Santa Clara (UEMG), 2008.

VALERY, Yolanda. Como descobrir tudo o que o google sabe de você - e como apagar seu rastro. BBC Mundo de 20 de julho de 2016. Disponível em: www.bbc.com/portuguese/ geral-36833505

GREENGARD, Samuel. The Internet of Things. The MIT Press Essential Knowledge Series. Cambridge. 2015.

THACKARA, John. The Design Challenge of Pervasive Computing. Interactions may-jun 2001. pp.4751

COLLS, Robert. Orwell in America. Oxford University Press`s, 15 de dezembro de 2013. Disponível em https://blog.oup.com/2013/12/orwell-in-america/ (Acesso em 14 de junho de 2017) 